\title{
Stilbazolium dyes containing rare-earth ions
}

\author{
Koen Binnemans* \\ K.U. Leuven, Department of Chemistry, Coordination Chemistry Division, Celestijnenlaan 200F, B-3001 Heverlee (Leuven), Belgium
}

Received 31 March 1999; accepted 22 September 1999

\begin{abstract}
The synthesis, thermal and spectroscopic properties of 28 rare-earth containing stilbazolium dyes are described. The complexes are prepared by reaction of the corresponding stilbazolium bromide (hemicyanine bromide) with a lanthanide salt and with a pyrazolone or a $\beta$-diketone. The bromide is replaced by a tetrakis pyrazolonato or by a tetrakis $\beta$-diketonato lanthanide(III) counter ion. $\subset 2000$ Elsevier Science S.A. All rights reserved.
\end{abstract}

Keywords: Lanthanides; Rare earths; Hemicyanine; Stilbazolium; Dye stuff; Solvatochromism

\section{Introduction}

Stilbazolium dyes (also called hemicyanine dyes) with halide counter ions were the subject of several studies, because of the nonlinear optical properties of these compounds [1-3]. The nonlinear optical effects are observed both in solution and in organised systems such as Langmuir-Blodgett films or single crystals. Wang et al. [4] synthesised stilbazolium dyes with a lanthanide complex acting as the counter ion, instead of a bromide (Fig. 1). The use of a dysprosium complex as the counter ion not only improved the film-forming properties, but also led to higher values for the second-order hyperpolarisability $\beta$. The group of C.H. Huang prepared several analogous stilbazolium complexes, with different $\beta$-diketonate ligands and lanthanide(III) ions [5-10]. Another interesting property of this type of compounds, besides the nonlinear optical properties, is the generation of a photoelectrical signal. A double lipid membrane doped with a Yb-complex containing the stilbazolium (hemicyanine) chromophore shows a small electric current through the membrane when illuminated with a continuous light source [11].

In this paper, we describe the synthesis of 28 stilbazolium dyes containing rare-earth ions. More particularly, we varied the chain length of the alkyl chain of the

*Tel.: +32-16-327-446; fax: +32-16-327-992.

E-mail address: koen.binnemans@chem.kuleuven.ac.be (K. Binnemans) stilbazolium chromophore and we varied the lanthanide(III) ion and the ligand in the anionic complex. The aim of this study is to determine the influence of these substitutions on the spectroscopic and thermal properties of these metal complexes. We investigated how the melting points of the complexes change as a function of the lanthanide contraction and as a function of the chain length. The change of the spectroscopic properties upon changing the pyrazolone by the $\beta$-diketone 1,3 -diphenyl1,3-propanedione was investigated. A strong solvatochromism was observed for the dyes dissolved in different organic solvents. Evidence was sought for the observability of $\mathrm{f}-\mathrm{f}$ transitions in the presence of the broad strong absorption by the organic ligands in the visible part of the spectrum.

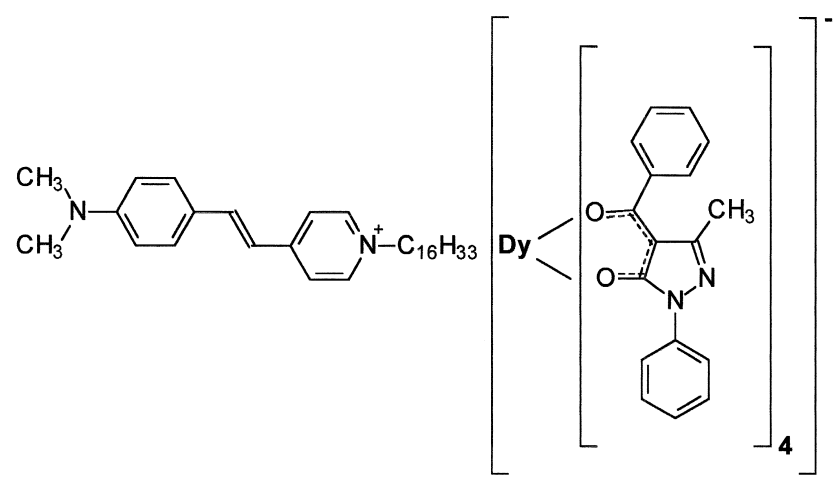

Fig. 1. Stilbazolium dye with a tetrakis(pyrazolonato)dysprosium(III) complex as the counter ion. Synthesised by Wang et al. [4]. 
Table 1

Overview and analytical results of the stilbazolium dyes with $\operatorname{Ln}(\mathrm{PMBP})_{4}^{-}$counter ions ${ }^{\mathrm{a}}$

\begin{tabular}{|c|c|c|c|c|c|c|c|c|}
\hline No. & $\mathrm{Ln}$ & $\mathrm{R}$ & $\% \operatorname{Ln}^{\mathrm{b}}$ & $\% \mathrm{C}^{\mathrm{b}}$ & $\% \mathrm{H}^{\mathrm{b}}$ & $\% \mathrm{~N}^{\mathrm{b}}$ & Yield (\%) & m.p. $\left({ }^{\circ} \mathrm{C}\right)$ \\
\hline 7 & $\mathrm{Eu}$ & $\mathrm{C}_{14} \mathrm{H}_{29}$ & n.d. $(9.0)^{\mathrm{c}}$ & $68.9(69.2)$ & $5.8(5.8)$ & $8.2(8.3)$ & 74 & 157 \\
\hline 8 & $\mathrm{Gd}$ & $\mathrm{C}_{14} \mathrm{H}_{29}$ & $9.8(9.3)$ & $68.6(69.0)$ & $5.6(5.8)$ & $8.2(8.3)$ & 76 & 161 \\
\hline 9 & $\mathrm{~Tb}$ & $\mathrm{C}_{14} \mathrm{H}_{29}$ & n.d. (9.4) & $68.7(69.0)$ & $5.7(5.8)$ & $8.2(8.3)$ & 37 & 157 \\
\hline 10 & $\mathrm{La}$ & $\mathrm{C}_{16} \mathrm{H}_{33}$ & n.d. (8.2) & $69.8(70.0)$ & $5.6(6.0)$ & $8.0(8.3)$ & 53 & 141 \\
\hline 11 & $\mathrm{Ce}$ & $\mathrm{C}_{16} \mathrm{H}_{33}$ & n.d. (8.3) & $69.9(70.0)$ & $5.9(6.0)$ & $8.0(8.2)$ & 61 & 152 \\
\hline 12 & $\operatorname{Pr}$ & $\mathrm{C}_{16} \mathrm{H}_{33}$ & $8.1(8.3)$ & $69.9(70.0)$ & $6.1(6.0)$ & $8.1(8.2)$ & 73 & 149 \\
\hline 13 & $\mathrm{Nd}$ & $\mathrm{C}_{16} \mathrm{H}_{33}$ & n.d. $(8.5)$ & $69.4(69.8)$ & $5.9(6.0)$ & $8.2(8.2)$ & 20 & 155 \\
\hline 14 & $\mathrm{Sm}$ & $\mathrm{C}_{16} \mathrm{H}_{33}$ & $9.0(8.8)$ & $69.4(69.6)$ & $5.9(6.0)$ & $8.0(8.2)$ & 69 & 159 \\
\hline 15 & $\mathrm{Eu}$ & $\mathrm{C}_{16} \mathrm{H}_{33}$ & n.d. (8.9) & $69.3(69.5)$ & $5.9(6.0)$ & $8.1(8.2)$ & 40 & 162 \\
\hline 16 & $\mathrm{Gd}$ & $\mathrm{C}_{16} \mathrm{H}_{33}$ & $8.9(9.2)$ & $69.0(69.3)$ & $6.1(5.9)$ & $8.1(8.2)$ & 65 & 162 \\
\hline 17 & $\mathrm{~Tb}$ & $\mathrm{C}_{16} \mathrm{H}_{33}$ & n.d. (9.3) & $69.1(69.2)$ & $5.9(5.9)$ & $8.0(8.2)$ & 65 & 164 \\
\hline 18 & Dy & $\mathrm{C}_{16} \mathrm{H}_{33}$ & n.d. (9.4) & $68.9(69.1)$ & $5.7(5.9)$ & $7.9(8.1)$ & 75 & 167 \\
\hline 19 & Ho & $\mathrm{C}_{16} \mathrm{H}_{33}$ & $9.4(9.6)$ & $68.5(68.9)$ & $5.7(5.9)$ & $7.9(8.1)$ & 46 & 163 \\
\hline 20 & $\mathrm{Er}$ & $\mathrm{C}_{16} \mathrm{H}_{33}$ & $9.5(9.7)$ & $68.5(68.9)$ & $5.8(5.9)$ & $8.1(8.1)$ & 63 & 165 \\
\hline 21 & $\mathrm{Tm}$ & $\mathrm{C}_{16} \mathrm{H}_{33}$ & n.d. (9.8) & $68.5(68.8)$ & $5.7(5.9)$ & $7.9(8.1)$ & 22 & 163 \\
\hline 22 & $\mathrm{Yb}$ & $\mathrm{C}_{16} \mathrm{H}_{33}$ & $10.4(10.0)$ & $68.5(68.7)$ & $5.8(5.9)$ & $7.9(8.1)$ & 52 & 160 \\
\hline 23 & $\mathrm{Lu}$ & $\mathrm{C}_{16} \mathrm{H}_{33}$ & $10.6(10.1)$ & $68.6(68.6)$ & $6.0(5.9)$ & $8.1(8.1)$ & 65 & 161 \\
\hline 24 & $\mathrm{Nd}$ & $\mathrm{C}_{18} \mathrm{H}_{37}$ & n.d. (8.3) & $70.1(70.1)$ & $5.9(6.1)$ & $7.9(8.1)$ & 78 & 154 \\
\hline 25 & $\mathrm{Eu}$ & $\mathrm{C}_{18} \mathrm{H}_{37}$ & n.d. (8.7) & $70.1(69.8)$ & $6.0(6.1)$ & $7.9(8.1)$ & 66 & 163 \\
\hline 26 & $\mathrm{Gd}$ & $\mathrm{C}_{18} \mathrm{H}_{37}$ & $9.5(9.0)$ & $70.0(69.6)$ & $5.8(6.1)$ & $7.8(8.0)$ & 64 & 163 \\
\hline 27 & $\mathrm{~Tb}$ & $\mathrm{C}_{18} \mathrm{H}_{37}$ & $9.4(9.1)$ & $69.8(69.5)$ & $5.7(6.1)$ & $7.8(8.0)$ & 71 & 170 \\
\hline
\end{tabular}

${ }^{\text {a }} \mathrm{PMBP}=1$-phenyl-3-methyl-4-benzoyl-5-pyrazolonato group.

${ }^{\mathrm{b}}$ Calculated values in parentheses.

${ }^{c}$ n.d.: not determined.

\section{Results and discussion}

An overview of the complexes can be found in Tables 1 and 2. The stilbazolium bromides 4-6 are synthesised by a two-step reaction (Scheme 1). During the first step, an alkyl chain is attached to the nitrogen atom of 4-picoline (4-methylpyridine). 4-Picoline is heated at reflux with an $n$-bromoalkane in ethanol. The crude product is crystallised twice from a mixture of diethyl ether:ethanol. The resulting $N$-alkyl-4-methylpyridinium bromides 1-3 are condensed with 4-dimethylaminobenzaldehyde via a Knoevenagel-type reaction. The reagents are heated in absolute ethanol, with piperidine as the catalyst. The crude stilbazolium bromides are crystallised twice from a mixture ethanol:hexane. Only the trans-product $(E)$ is formed. There is no evidence for the formation of the cis-product, probably because of steric hindrance by the aromatic groups. The $N$-alkyl-methylpyridinium bromides $\mathbf{1 - 3}$ are white powders, whereas the stilbazolium bromides 4-6 have a very intense orange-red colour. The products are

Table 2

Overview and analytical results of the stilbazolium dyes with $\operatorname{Ln}(\mathrm{DBM})_{4}^{-}$counter ions $^{\mathrm{a}}$

\begin{tabular}{|c|c|c|c|c|c|c|c|c|}
\hline No. & Ln & $\mathrm{R}$ & $\% \operatorname{Ln}^{\mathrm{b}}$ & $\% \mathrm{C}^{\mathrm{b}}$ & $\% \mathrm{H}^{\mathrm{b}}$ & $\% \mathrm{~N}^{\mathrm{b}}$ & Yield (\%) & m.p. $\left({ }^{\circ} \mathrm{C}\right)$ \\
\hline 28 & $\mathrm{Eu}$ & $\mathrm{C}_{14} \mathrm{H}_{29}$ & n.d. $(10.4)^{\mathrm{c}}$ & $72.6(72.9)$ & $6.0(6.1)$ & $1.9(1.9)$ & 74 & 213 \\
\hline 29 & $\mathrm{~Tb}$ & $\mathrm{C}_{14} \mathrm{H}_{29}$ & $10.4(10.8)$ & $72.6(72.5)$ & $5.9(6.1)$ & $2.0(1.9)$ & 66 & 218 \\
\hline 30 & $\mathrm{Eu}$ & $\mathrm{C}_{16} \mathrm{H}_{33}$ & $10.7(10.2)$ & $72.6(73.1)$ & $6.0(6.3)$ & $1.8(1.8)$ & 78 & 202 \\
\hline 31 & $\mathrm{Gd}$ & $\mathrm{C}_{16} \mathrm{H}_{33}$ & n.d. (10.5) & $72.2(72.9)$ & $6.0(6.2)$ & $1.7(1.9)$ & 72 & 206 \\
\hline 32 & $\mathrm{~Tb}$ & $\mathrm{C}_{16} \mathrm{H}_{33}$ & $11.1(10.6)$ & $72.4(72.8)$ & $6.0(6.2)$ & $1.8(1.9)$ & 54 & 206 \\
\hline 33 & $\mathrm{Eu}$ & $\mathrm{C}_{18} \mathrm{H}_{37}$ & $10.1(10.0)$ & $73.0(73.4)$ & $6.2(6.4)$ & $1.7(1.8)$ & 77 & 213 \\
\hline 34 & $\mathrm{~Tb}$ & $\mathrm{C}_{18} \mathrm{H}_{37}$ & n.d. $(10.4)$ & $72.8(73.0)$ & $6.3(6.4)$ & $1.8(1.8)$ & 86 & 218 \\
\hline
\end{tabular}

${ }^{\mathrm{a}} \mathrm{DBM}=$ dibenzoylmethanato or 1,3-diphenyl-1,3-propanedionato group.

${ }^{\mathrm{b}}$ Calculated values in parentheses.

${ }^{\mathrm{c}}$ n.d.: not determined. 

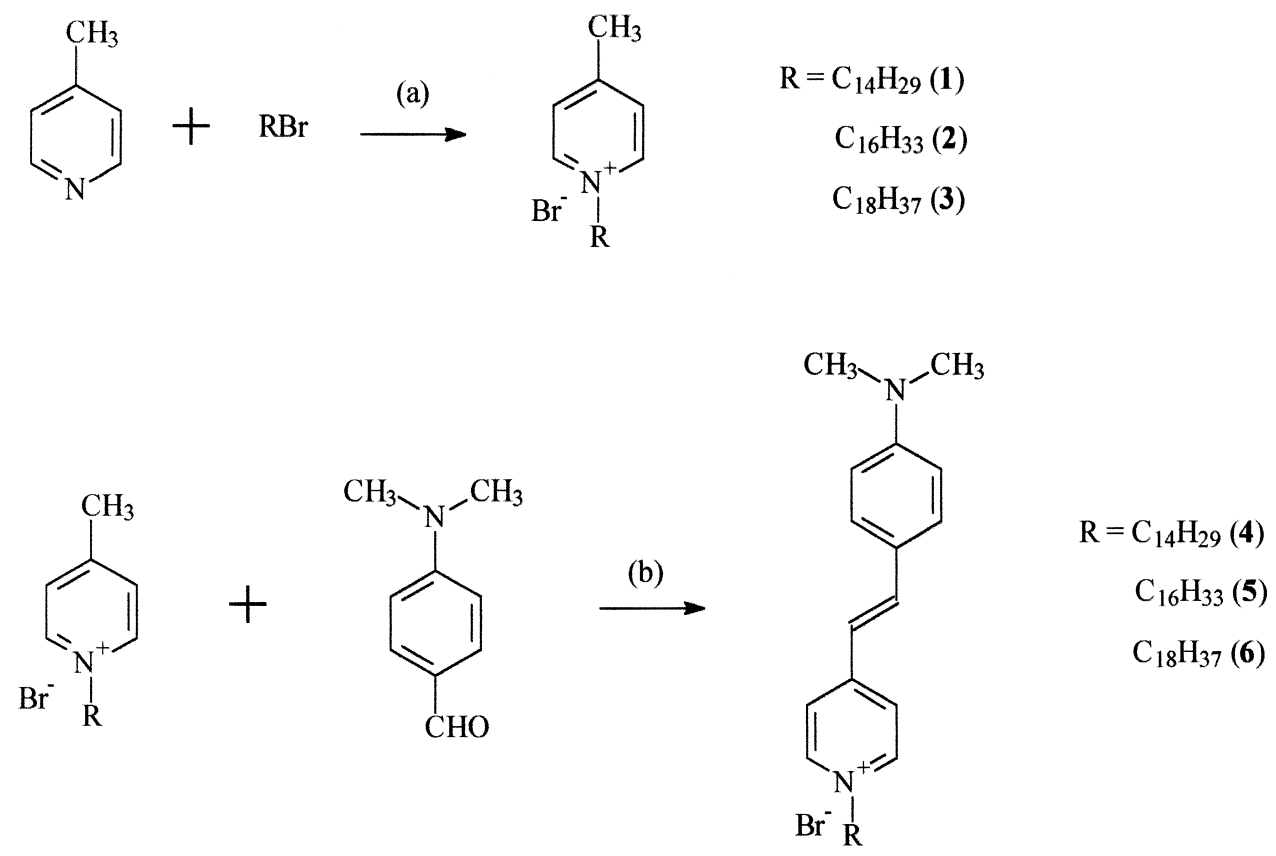

Scheme 1. Synthesis of the stilbazolium bromides. Experimental conditions: (a) ethanol (reflux, 24 h); (b) ethanol (reflux, 4 h); piperidine (catalyst).

characterised by NMR, IR-spectroscopy and CHN microanalysis.

The lanthanide complexes 7-34 were synthesised by reaction of the corresponding stilbazolium bromide with a lanthanide salt and with the pyrazolone, 4-benzoyl-3methyl-1-phenyl-2-pyrazolin-5-one or with the $\beta$-diketone, 1,3-diphenyl-1,3-propanedione (dibenzoylmethane, DBM). First the pyrazolone or the $\beta$-diketone was deprotonated by an equivalent amount of $\mathrm{NaOH}$. Then, the lanthanide salt and the stilbazolium bromide were added to the deprotonated pyrazolone or $\beta$-diketone. Addition of the lanthanide salt was done dropwise. The molar ratio of pyrazolone (or $\beta$-diketone):stilbazolium bromide:lanthanide salt was $4: 1: 1$. For the lanthanide salt, one can either use the hydrated nitrate or the hydrated chloride salt. All the reactions were done in ethanol. The lanthanide complexes were characterised by CHN microanalysis and by IR spectroscopy. The lanthanide content of a selected number of complexes was determined gravimetrically as the 8hydroxyquinoline complex. The analysis results revealed that the complexes are anhydrous and that four pyrazolone or $\beta$-diketone ligands and one stilbazolium group are present for each lanthanide ion.

The stilbazolium bromides 4-6 are thermotropic liquid crystals, forming a smectic A ( $\mathrm{SmA})$ mesophase. The mesomorphic behaviour of these compounds is described in detail elsewhere [12]. The metal complexes 7-34 synthesised by replacing the bromide ion of the stilbazolium bromides 4-6 by the bulky tetrakis(pyrazolonato)lanthanide(III) or the tetrakis( $\beta$-diketonato)lanthanide(III) anions do not show mesophases, but have a single melting point. For the complexes based on the pyrazolone, the melting point increases sharply in the beginning of the lanthanide series, but remains rather constant over the second half of the lanthanide series. Ionic liquid crystals possess a strong tendency to form smectic mesophases, i.e. molecular organisation in layers, because of the electrostatic attraction. Therefore, the formation of a smectic A mesophase by the stilbazolium bromides 4-6 is explainable. However, the lanthanide-containing anions are too bulky to maintain the organisation of the cationic stilbazolium molecules in layers and with their molecular long axis parallel to each other. Because of the absence of the necessary conditions for molecular organisation, no mesophase can be formed.

The absorption spectra of the stilbazolium bromide ligand 5 and of the lanthanide complexes 10, 16, 23 and 31 were recorded in different organic solvents. The solvents were chosen in such a way that both polar and apolar, protic and aprotic solvents were present: acetone, acetonitrile, 1-butanol, 2-butanone, chlorobenzene, chloroform, 1,2-dichloroethane, dichloromethane (DCM), 1,4-dioxane, dimethylsulphoxide (DMSO), ethanol, methanol, 1-pentanol, 1-propanol, pyridine, tetrahydrofuran (THF). None of the compounds was soluble in water or in toluene. The colour of the solutions ranges from yellow to intense orange red, depending on the solvent used (yellow in THF, orange-red in DCM). This is an evidence for the solvatochromic properties of the compounds containing the stilbazolium chromophore. The spectra in the visible region are very comparable for both the stilbazolium bromides and the lanthanide complexes. In Fig. 2, the absorption spectra of the stilbazolium bromide $\mathbf{5}$ and of the lanthanide complexes $\mathbf{1 0}$ and $\mathbf{3 1}$ in chloroform are shown. The colour of the solutions is due to an intense charge transfer band at $497 \mathrm{~nm}$ in the stilbazolium bromide $\mathbf{5}$, and 


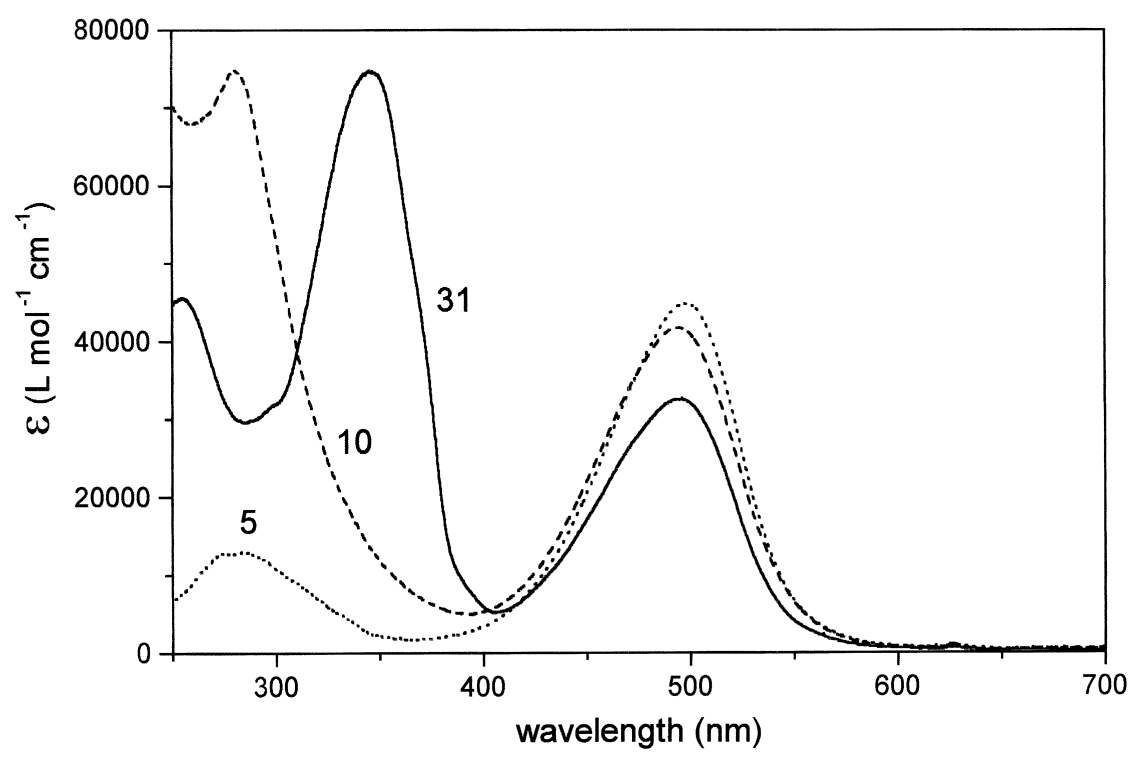

Fig. 2. Absorption spectra of the stilbazolium bromide $\mathbf{5}$ and of the lanthanide complexes $\mathbf{1 0}$ and $\mathbf{3 1}$ in chloroform.

between 493 and $496 \mathrm{~nm}$ for the lanthanide complexes. Fig. 3 shows the absorption spectra of the La-compound $\mathbf{1 0}$ in different solvents. The $\epsilon$ values vary between 39000 and $440001 \mathrm{~mol}^{-1} \mathrm{~cm}^{-1}$. Depending on the solvent, the peak maximum can move over more than $50 \mathrm{~nm}$ [13]. The charge transfer band originates from charge transfer from the anionic lanthanide complex to the cationic stilbazolium chromophore. In the UV part of the spectrum, a $\pi \rightarrow \pi^{*}$ transition due to the aromatic groups is observed [14]. This $\pi \rightarrow \pi^{*}$ transition is much more intense for the lanthanide complexes than for the stilbazolium bromide. Depending on the solvent, the $\epsilon$ values of this transition range between 8700 and $122001 \mathrm{~mol}^{-1} \mathrm{~cm}^{-1}$ for the stilbazolium bromide 5 and between 68400 and 84500
$1 \mathrm{~mol}^{-1} \mathrm{~cm}^{-1}$ for the La-complex 10. This increase is due to the aromatic rings of the pyrazolone groups. Thus, the $\pi \rightarrow \pi^{*}$ transition is more intense than the charge transfer band in the lanthanide complexes, but not in the stilbazolium bromide $\mathbf{5}$. For the complex with the $\beta$-diketone ligand, the $\pi \rightarrow \pi^{*}$ transition is shifted to longer wavelengths in comparison to the complexes with the pyrazolone ligand. In solvents which are transparent to wavelengths smaller than $250 \mathrm{~nm}$, a third transition can be observed in the solution spectra of the complexes. This transition is assigned to a $n \rightarrow \pi^{*}$ transition within the carbonyl groups. Depending on the solvent, the $\epsilon$ values of this transition range between 61400 and 77500 $1 \mathrm{~mol}^{-1} \mathrm{~cm}^{-1}$ for the La-complex $\mathbf{1 0}$ and between 45400

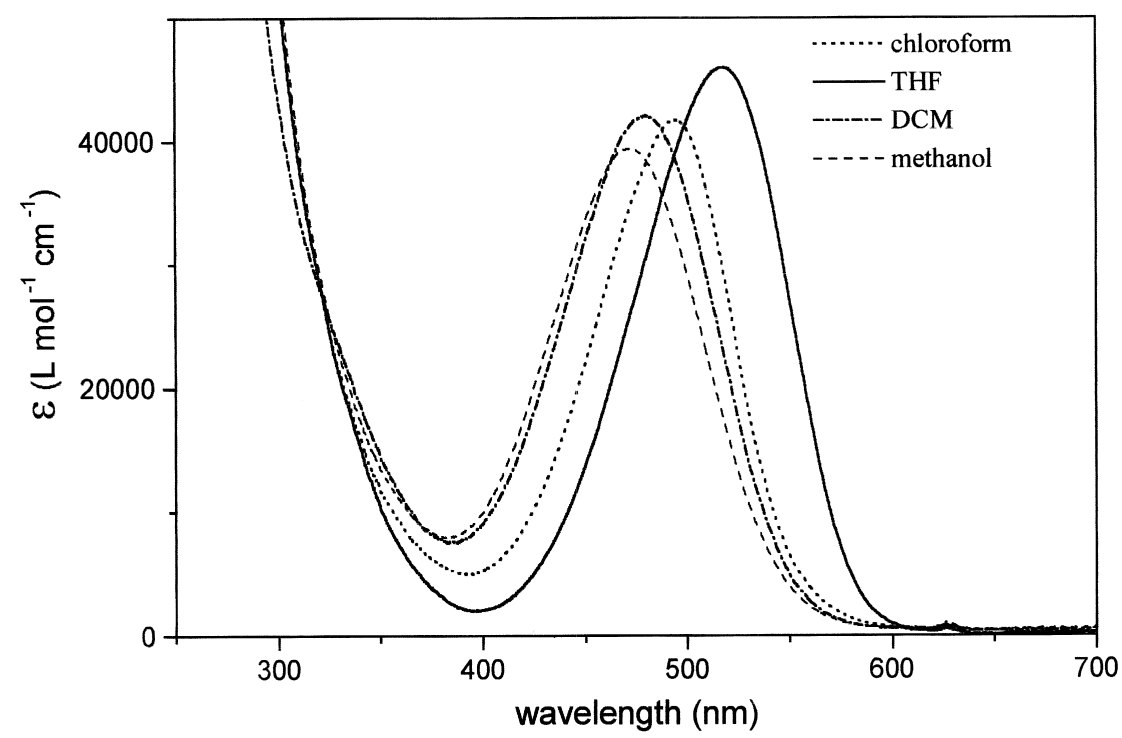

Fig. 3. Absorption spectra of the La-complex $\mathbf{1 0}$ in chloroform, THF, dichloromethane (DCM) and methanol (conc. $\left.1.0 \times 10^{-5} \mathrm{M}\right)$. 
and $663001 \mathrm{~mol}^{-1} \mathrm{~cm}^{-1}$ for the Gd-complex 31. The nature of the lanthanide ion has a negligible influence on the spectral behaviour: $\mathrm{La}^{3+}$ can be replaced by $\mathrm{Gd}^{3+}$ or $\mathrm{Lu}^{3+}$ without significantly changing the spectroscopic properties.

It is very difficult to observe the $\mathrm{f}-\mathrm{f}$ transitions of the trivalent lanthanide ions in these complexes, because of the very strong light absorption by the organic ligands in comparison to the very weak Laporte forbidden $\mathrm{f}-\mathrm{f}$ transitions. Whereas for the absorption spectra of the of the ligands we typically used a concentration of $1.0 \times 10^{-5} \mathrm{M}$ and an optical path length of $1.0 \mathrm{~cm}$, an absorption cell of $10 \mathrm{~cm}$ was necessary to observe the $\mathrm{f}-\mathrm{f}$ transitions at concentration of $0.01 \mathrm{M}$. Under these conditions, the ligand cut-off is observed at ca. $620 \mathrm{~nm}$. Only a limited number of trivalent lanthanide ions possess intense absorption bands in the 600 to $1000 \mathrm{~nm}$ spectral region: $\mathrm{Nd}^{3+}$, $\mathrm{Dy}^{3+}, \mathrm{Ho}^{3+}, \mathrm{Er}^{3+}$ and $\mathrm{Tm}^{3+}$. Detection of $\mathrm{f}-\mathrm{f}$ transitions further to the infrared is impossible because of overtones of vibrational transitions in the complexes and in the solvents. The dipole strength of the transition (expressed in Debye $^{2}$ ) was extracted from the absorption spectrum, using the formula:

$D=\frac{1}{108.9 C d} \int \frac{A(\bar{\nu})}{\bar{\nu}} d \bar{\nu}$

where $C$ is the concentration of the lanthanide ion $\left(\mathrm{mol} \mathrm{l} \mathrm{l}^{-1}\right), d$ is the optical path length $(\mathrm{cm}), A$ is the absorbance $\left[A=-\log \left(I / I_{0}\right)\right]$ and $\bar{\nu}$ is the wavenumber $\left(\mathrm{cm}^{-1}\right)$. The absorbance is related to the molar absorptivity $\epsilon$ via Lambert-Beer's law: $A=\epsilon C d$. The intensity results for the Nd-complex $\mathbf{1 3}$ in chloroform are summarised in Table 3. Because of the limited number of transitions observed in the spectrum, it was not possible to extract a reliable set of the Judd-Ofelt intensity parameters $\Omega_{\lambda}$ ( $\lambda=2,4$ and 6) [15-17]. We compared the intensities of the transitions we could observe with the intensities of the corresponding transitions of the $\mathrm{Nd}^{3+}$ ion in aqueous solution [18]. Because the ratios $D_{\text {complex }} / D_{\text {aquo }}$ vary between 1.2 and 2.0 , we can conclude that the intensity of the transitions of the complexes are comparable with that of the neodymium ion in water. It was impossible to observe the hypersensitive transition ${ }^{4} \mathrm{G}_{5 / 2},{ }^{2} \mathrm{G}_{7 / 2} \leftarrow{ }^{4} \mathrm{I}_{9 / 2}$ at circa $17200 \mathrm{~cm}^{-1}$. The luminescence spectrum of the Eu(III) complex 15 dissolved in dichloromethane (concentration of the solution was $1.0 \times 10^{-4} \mathrm{M}$ ) was recorded. By excitation at $521 \mathrm{~nm}$, the solution showed a very strong red luminescence. However, we didn't observe the emission line typical for the trivalent europium ion, but a broad-band spectrum due to luminescence by the stilbazolium group. The same luminescence spectrum was observed for a solution of the stilbazolium bromide $\mathbf{5}$ in dichloromethane.

\section{Conclusions}

We synthesised 28 rare-earth complexes containing the stilbazolium chromophore, by replacing the bromide ion in the corresponding stilbazolium bromides by a tetrakis pyrazolonato or by a $\beta$-diketonato lanthanide(III) counter ion. All the complexes melt directly to an isotropic liquid, without passing through a mesophase. The melting point increases sharply in the beginning of the lanthanide series, and remains constant over the second half of the series. The rare-earth complexes dissolved in organic solvents show strong solvatochromism (yellow to orange colour).

\section{Experimental details}

\subsection{General}

${ }^{1} \mathrm{H}$ NMR spectra were recorded on either a Bruker WM $250(250 \mathrm{MHz})$ or a Bruker AMX 400 spectrometer (400 $\mathrm{MHz}$ ). $\mathrm{CDCl}_{3}$ was used as the solvent and tetramethylsilane (TMS) as internal standard. The $\delta$-values are expressed in ppm. IR spectra were recorded on a Bruker FTIR spectrometer IFS66, using the KBr-pellet technique. CHN microanalysis data were obtained at the Universities of Exeter (UK) or Sheffield (UK). The rare-earth content in the complexes was determined gravimetrically as described in Section 4.3. Transition temperatures were determined by differential scanning calorimetry (DSC) with a Mettler-Toledo DSC821e module. The samples were heated or cooled at a constant rate of $10^{\circ} \mathrm{C} \mathrm{min}{ }^{-1}$. Optical textures were observed with an Olympus BX60 polarising microscope with a Linkam TMS600 hot stage and a Linkam TMS93 temperature-controller. Absorption spectra were recorded at room temperature on a Shimadzu UV-3100 spectrophotometer, and luminescence spectra on a Shimadzu RF-5000 spectrofluorimeter.

Table 3

Transitions observed in the absorption spectrum of neodymium(III) complex $\mathbf{1 3}$ in chloroform

\begin{tabular}{llrl}
\hline Transition & Wavenumber $\left(\mathrm{cm}^{-1}\right)$ & Dipole strength $D\left(\right.$ Debye $\left.^{2}\right)$ & $D_{\text {complex }} / D_{\text {aquo }}$ \\
\hline${ }^{4} \mathrm{~F}_{3 / 2} \leftarrow{ }^{4} \mathrm{I}_{9 / 2}$ & 11420 & $5.3 \times 10^{-4}$ & 2.03 \\
${ }^{2} \mathrm{H}_{9 / 2},{ }^{4} \mathrm{~F}_{5 / 2} \leftarrow{ }^{4} \mathrm{I}_{9 / 2}$ & 12440 & $17.5 \times 10^{-4}$ & 1.31 \\
${ }^{4} \mathrm{~F}_{7 / 2},{ }^{4} \mathrm{~S}_{3 / 2} \leftarrow{ }^{4} \mathrm{I}_{9 / 2}$ & 13430 & $16.2 \times 10^{-4}$ & 1.19 \\
${ }^{4} \mathrm{~F}_{9 / 2} \leftarrow{ }^{4} \mathrm{I}_{9 / 2}$ & 14570 & $1.0 \times 10^{-4}$ & 1.57 \\
\hline
\end{tabular}




\subsection{Synthesis}

\subsubsection{1-Tetradecyl-4-methylpyridinium bromide 1}

Heat a mixture of 4-picoline $(0.20 \mathrm{~mol}, 18.63 \mathrm{~g})$ and 1-bromotetradecane $(0.22 \mathrm{~mol}, 61.00 \mathrm{~g})$ for $24 \mathrm{~h}$ at reflux in absolute ethanol $(30 \mathrm{ml})$. Cool the mixture to ambient temperature, filter on a Büchner funnel and wash with diethyl ether $(75 \mathrm{ml})$. Crystallise the crude product twice from diethyl ether:ethanol. Filter the purified product and wash with diethyl ether $(2 \times 100 \mathrm{ml})$. Dry in vacuo. Product $\mathbf{1}$ is obtained as white crystals in $83 \%$ yield $(61.8$ g) - ${ }^{1} \mathrm{H} \mathrm{NMR}\left(\delta, \mathrm{CDCl}_{3}, 400 \mathrm{MHz}\right): 0.86\left(\mathrm{t}, 3 \mathrm{H}, \mathrm{CH}_{3}\right)$, $1.27\left(\mathrm{~m}, 22 \mathrm{H},\left(\mathrm{CH}_{2}\right)_{11}\right), 2.00$ (quintet, $\left.2 \mathrm{H}, \mathrm{CH}_{2}\right), 2.67$ (s, $3 \mathrm{H}, \mathrm{CH}_{3}$-aryl), $4.92\left(\mathrm{t}, 2 \mathrm{H}, \mathrm{N}^{+} \mathrm{CH}_{2^{-}}\right), 7.89(\mathrm{~d}, 2 \mathrm{H}$, $\mathrm{H}$-aryl, $\left.J_{\mathrm{o}}=6.5 \mathrm{~Hz}\right), 9.31\left(\mathrm{~d}, 2 \mathrm{H}, \mathrm{H}\right.$-aryl, $\left.J_{\mathrm{o}}=6.5 \mathrm{~Hz}\right)-$ m.p. $77^{\circ} \mathrm{C}$ (diethyl ether:ethanol) - Anal. $\mathrm{C}_{20} \mathrm{H}_{36} \mathrm{BrN}$ $\left(M_{\mathrm{w}}=370.42 \mathrm{~g} \mathrm{~mol}^{-1}\right)$ : Found $\mathrm{C}, 64.61 ; \mathrm{H}, 10.22 ; \mathrm{N}$, $3.61 \%$. Calc. C, 64.85; H, 9.80; N, 3.78\%.

\subsubsection{1-Hexadecyl-4-methylpyridinium bromide 2}

Same procedure as for $\mathbf{1}$, but with 1-bromohexadecane $(0.22 \mathrm{~mol}, 67.17 \mathrm{~g})$. Product $\mathbf{2}$ is obtained as white crystals in $85 \%$ yield $(67.8 \mathrm{~g})-{ }^{1} \mathrm{H} \operatorname{NMR}\left(\delta, \mathrm{CDCl}_{3}, 250 \mathrm{MHz}\right)$ : $0.89\left(\mathrm{t}, 3 \mathrm{H}, \mathrm{CH}_{3}\right), 1.26\left(\mathrm{~m}, 26 \mathrm{H},-\left(\mathrm{CH}_{2}\right)_{13}\right), 2.04(\mathrm{~m}, 2$ $\mathrm{H}, \mathrm{CH}_{2}$ ), 2.69 (s, $3 \mathrm{H}, \mathrm{CH}_{3}$-aryl), 4.92 (t, $2 \mathrm{H}, \mathrm{N}^{+} \mathrm{CH}_{2}-$ ), 7.94 (d, $2 \mathrm{H}, \mathrm{H}$-aryl, $\left.J_{\mathrm{o}}=6 \mathrm{~Hz}\right), 9.39$ (d, $2 \mathrm{H}, \mathrm{H}$-aryl, $J_{\mathrm{o}}=6$ $\mathrm{Hz}$ - m.p. $83^{\circ} \mathrm{C}$ (diethyl ether:ethanol) - Anal. $\mathrm{C}_{22} \mathrm{H}_{40} \mathrm{BrN}\left(M_{\mathrm{w}}=398.47 \mathrm{~g} \mathrm{~mol}^{-1}\right)$ : Found C, 66.20; H, $10.32 ; \mathrm{N}, 3.37 \%$. Calc. C, 66.31; H, 10.12; N, $3.52 \%$.

\subsubsection{1-Octadecyl-4-methylpyridinium bromide $\mathbf{3}$}

Same procedure as for $\mathbf{1}$, but with 1-bromooctadecane $(0.22 \mathrm{~mol}, 73.35 \mathrm{~g})$. Product $\mathbf{3}$ is obtained as white crystals in $95 \%$ yield $(81.4 \mathrm{~g})-{ }^{1} \mathrm{H} \mathrm{NMR}\left(\delta, \mathrm{CDCl}_{3}, 400 \mathrm{MHz}\right)$ : $0.86\left(\mathrm{t}, 3 \mathrm{H}, \mathrm{CH}_{3}\right), 1.26\left(\mathrm{~m}, 30 \mathrm{H},-\left(\mathrm{CH}_{2}\right)_{15}\right), 2.10$ (quintet, $2 \mathrm{H}, \mathrm{CH}_{2}$ ), $2.67\left(\mathrm{~s}, 3 \mathrm{H}, \mathrm{CH}_{3}\right.$-aryl), $4.92(\mathrm{t}, 2 \mathrm{H}$, $\left.\mathrm{N}^{+} \mathrm{CH}_{2^{-}}\right), 7.90\left(\mathrm{~d}, 2 \mathrm{H}, \mathrm{H}\right.$-aryl, $\left.J_{\mathrm{o}}=6.5 \mathrm{~Hz}\right), 9.34(\mathrm{~d}, 2 \mathrm{H}$, $\mathrm{H}$-aryl, $\left.J_{\mathrm{o}}=6.5 \mathrm{~Hz}\right)-$ m.p. $93^{\circ} \mathrm{C}$ (diethyl ether:ethanol) - Anal. $\mathrm{C}_{24} \mathrm{H}_{44} \mathrm{BrN}\left(M_{\mathrm{w}}=426.52 \mathrm{~g} \mathrm{~mol}^{-1}\right)$ : Found $\mathrm{C}$, 67.34; H, 10.31; N, 3.23\%. Calc. C, 67.58; H, 10.40; N, $3.28 \%$.

\subsection{4. (E)-N-Tetradecyl-4- $\left(N^{\prime}, N^{\prime}-\right.$}

dimethylamino)stilbazolium bromide 4

Add piperidine $(5 \mathrm{ml})$ to a mixture of $1(0.05 \mathrm{~mol}, 18.52$ $\mathrm{g})$ and 4-dimethylaminobenzaldehyde (0.05 mol, $7.46 \mathrm{~g})$ in absolute ethanol $(75 \mathrm{ml})$. Reflux for $4 \mathrm{~h}$ with stirring and under dry nitrogen atmosphere. Cool the mixture to ambient temperature and chill in a salted ice bath. Filter the precipitate and wash with cold absolute ethanol $(2 \times 50$ $\mathrm{ml})$. Crystallise twice from a ethanol:heptane (1:1) mixture, filter and wash with cold absolute ethanol $(2 \times 20 \mathrm{ml})$. Product 4 is obtained as a orange-red crystalline powder in $58 \%$ yield $(14.5 \mathrm{~g})-{ }^{1} \mathrm{H} \mathrm{NMR}\left(\delta, \mathrm{CDCl}_{3}, 400 \mathrm{MHz}\right)$ : $0.88\left(\mathrm{t}, 3 \mathrm{H}, \mathrm{CH}_{3}\right), 1.28\left(\mathrm{~m}, 22 \mathrm{H},\left(\mathrm{CH}_{2}\right)_{11}\right), 1.92$ (quintet, $\left.2 \mathrm{H}, \mathrm{CH}_{2}\right), 3.06\left(\mathrm{~s}, 6 \mathrm{H},\left(\mathrm{CH}_{3}\right)_{2} \mathrm{~N}\right), 4.64\left(\mathrm{t}, 2 \mathrm{H}, \mathrm{N}^{+} \mathrm{CH}_{2}\right)$, $6.67\left(\mathrm{~d}, 2 \mathrm{H}, \operatorname{aryl}-\mathrm{H}, J_{\mathrm{o}}=9 \mathrm{~Hz}\right), 6.85(\mathrm{~d}, 1 \mathrm{H},-\mathrm{CH}=$, $\left.J_{\text {trans }}=16 \mathrm{~Hz}\right), 7.51\left(\mathrm{~d}, 2 \mathrm{H}, \mathrm{H}\right.$-aryl, $\left.J_{\mathrm{o}}=9 \mathrm{~Hz}\right), 7.67(\mathrm{~d}, 1$ $\left.\mathrm{H},-\mathrm{CH}=, J_{\text {trans }}=16 \mathrm{~Hz}\right), 7.87\left(\mathrm{~d}, 2 \mathrm{H}\right.$, aryl-H, $\left.J_{\mathrm{o}}=7 \mathrm{~Hz}\right)$, 8.94 (d, 2 H, H-aryl, $\left.J_{\mathrm{o}}=7 \mathrm{~Hz}\right)-\mathrm{IR}\left(\mathrm{cm}^{-1}, \mathrm{KBr}\right): 3019$ (w), 2912 (s), 2848 (s), 1639 (s, alkene C=C), 1569 (w, aryl $\mathrm{C}=\mathrm{C}), 1517(\mathrm{~m}$, aryl C=C), $1466(\mathrm{~s}), 1376(\mathrm{w}), 1319(\mathrm{w})$, 1179 (m), 1042 (m), 826 (m), 708 (m), 553 (w) - Anal. $\mathrm{C}_{29} \mathrm{H}_{45} \mathrm{BrN}_{2}\left(M_{\mathrm{w}}=501.59 \mathrm{~g} \mathrm{~mol}^{-1}\right)$ : Found C, 69.05; H, 9.38; N, 5.20\%. Calc. C, 69.44; H, 9.04; N, 5.58\%.

\subsection{5. (E)-N-Hexadecyl-4- $\left(N^{\prime}, N^{\prime}-\right.$}

\section{dimethylamino)stilbazolium bromide $\mathbf{5}$}

Same procedure as for $\mathbf{4}$, but now starting with 2 (0.05 mol, $19.92 \mathrm{~g})$. Product $\mathbf{5}$ is obtained as a orange-red crystalline powder in $71 \%$ yield $(18.8 \mathrm{~g})-{ }^{1} \mathrm{H}$ NMR $(\delta$, $\left.\mathrm{CDCl}_{3}, 400 \mathrm{MHz}\right): 0.87\left(\mathrm{t}, 3 \mathrm{H}, \mathrm{CH}_{3}\right), 1.26(\mathrm{~m}, 26 \mathrm{H}$, $\left(\mathrm{CH}_{2}\right)_{13}$ ), 1.93 (quintet, $\left.2 \mathrm{H}, \mathrm{CH}_{2}\right), 3.06(\mathrm{~s}, 6 \mathrm{H}$, $\left.\left(\mathrm{CH}_{3}\right)_{2} \mathrm{~N}\right), 4.64\left(\mathrm{t}, 2 \mathrm{H}, \mathrm{N}^{+} \mathrm{CH}_{2}\right), 6.68(\mathrm{~d}, 2 \mathrm{H}$, aryl-H, $\left.J_{\mathrm{o}}=9 \mathrm{~Hz}\right), 6.86\left(\mathrm{~d}, 1 \mathrm{H},-\mathrm{CH}=, J_{\text {trans }}=16 \mathrm{~Hz}\right), 7.52(\mathrm{~d}, 2$ $\mathrm{H}, \mathrm{H}$-aryl, $\left.J_{\mathrm{o}}=9 \mathrm{~Hz}\right), 7.62\left(\mathrm{~d}, 1 \mathrm{H}, \mathrm{CH}=, J_{\text {trans }}=16 \mathrm{~Hz}\right)$, $7.88\left(\mathrm{~d}, 2 \mathrm{H}\right.$, aryl-H, $\left.J_{\mathrm{o}}=7 \mathrm{~Hz}\right), 8.94\left(\mathrm{~d}, 2 \mathrm{H}, \mathrm{H}\right.$-aryl, $J_{\mathrm{o}}=7$ $\mathrm{Hz}$ - IR ( $\left.\mathrm{cm}^{-1}, \mathrm{KBr}\right): 3000$ (w), 2912 (s), 2852 (m), 1641 (m, alkene $\mathrm{C}=\mathrm{C}), 1591(\mathrm{~s}$, aryl $\mathrm{C}=\mathrm{C}), 1526$ (s, aryl $\mathrm{C}=\mathrm{C})$, 1467 (m), 1430 (m), 1362 (m), 1330 (m), 1161 (s), 827 (w), 717 (w), 518 (w) - Anal. $\mathrm{C}_{31} \mathrm{H}_{49} \mathrm{BrN}_{2} \quad\left(M_{\mathrm{w}}=529.65\right.$ $\mathrm{g} \mathrm{mol}^{-1}$ ): Found C, 69.94; H, 9.75; N, 4.88\%. Calc. C, 70.30; H, 9.32; N, 5.29\%.

\subsection{6. (E)-N-Octadecyl-4- $\left(N^{\prime}, N^{\prime}-\right.$}

dimethylamino)stilbazolium bromide 6

Same procedure as for $\mathbf{4}$, but now starting with $3(0.05$ mol, $21.33 \mathrm{~g})$. Product $\mathbf{6}$ is obtained as an orange-red crystalline powder in $74 \%$ yield $(20.6 \mathrm{~g})-{ }^{1} \mathrm{H}$ NMR $(\delta$, $\left.\mathrm{CDCl}_{3}, 400 \mathrm{MHz}\right): 0.88\left(\mathrm{t}, 3 \mathrm{H}, \mathrm{CH}_{3}\right), 1.24(\mathrm{~m}, 30 \mathrm{H}$, $\left.\left(\mathrm{CH}_{2}\right)_{15}\right), 1.95$ (quintet, $\left.2 \mathrm{H}, \mathrm{CH}_{2}\right), 3.06(\mathrm{~s}, 6 \mathrm{H}$, $\left.\left(\mathrm{CH}_{3}\right)_{2} \mathrm{~N}\right), 4.65\left(\mathrm{t}, 2 \mathrm{H}, \mathrm{N}^{+} \mathrm{CH}_{2}\right), 6.67(\mathrm{~d}, 2 \mathrm{H}$, aryl-H, $\left.J_{\mathrm{o}}=9 \mathrm{~Hz}\right), 6.85\left(\mathrm{~d}, 1 \mathrm{H},-\mathrm{CH}=, J_{\text {trans }}=16 \mathrm{~Hz}\right), 7.52(\mathrm{~d}, 2$ $\mathrm{H}, \mathrm{H}$-aryl, $\left.J_{\mathrm{o}}=9 \mathrm{~Hz}\right), 7.67\left(\mathrm{~d}, 1 \mathrm{H},-\mathrm{CH}=, J_{\text {trans }}=16 \mathrm{~Hz}\right)$, $7.88\left(\mathrm{~d}, 2 \mathrm{H}\right.$, aryl-H, $\left.J_{\mathrm{o}}=7 \mathrm{~Hz}\right), 8.94\left(\mathrm{~d}, 2 \mathrm{H}, \mathrm{H}\right.$-aryl, $J_{\mathrm{o}}=7$ $\mathrm{Hz}$ - IR ( $\left.\mathrm{cm}^{-1}, \mathrm{KBr}\right): 3009$ (w), 2912 (s), 2852 (m), 1641 (m, alkene $\mathrm{C}=\mathrm{C}), 1592$ (s, aryl $\mathrm{C}=\mathrm{C}), 1530(\mathrm{~m}$, aryl $\mathrm{C}=\mathrm{C})$, 1469 (m), 1434 (w), 1368 (m), 1328 (m), 1161 (m), 831 (w), $716(\mathrm{w}), 549(\mathrm{w})-$ Anal. $\mathrm{C}_{33} \mathrm{H}_{53} \mathrm{BrN}_{2}\left(M_{\mathrm{w}}=557.70\right.$ $\mathrm{g} \mathrm{mol}^{-1}$ ): Found C, 70.29; H, 9.81; N, 4.98\%. Calc. C, 70.07; H, 9.58; N, 5.02\%.

For the synthesis of the lanthanide complexes, we give two typical examples. All the other complexes were synthesised in an analogous manner:

\subsection{7. (E)-N-Hexadecyl-4-(2-(4-}

\section{dimethylaminophenyl)ethenyl)pyridinium tetrakis(4-} benzoyl-3- methyl-1-phenyl-2-pyrazolonato)

\section{lanthanum(III) 10}

Add compound 5 ( $2 \mathrm{mmol}, 1.06 \mathrm{~g}$ ), $\mathrm{NaOH}$ (8 mmol, 2 $\mathrm{M}$ solution) and $\mathrm{La}\left(\mathrm{NO}_{3}\right)_{3} \cdot 6 \mathrm{H}_{2} \mathrm{O}(2 \mathrm{mmol}, 0.88 \mathrm{~g})$ to a 
solution of 4-benzoyl-3-methyl-1-phenyl-2-pyrazolin-5-one $(8 \mathrm{mmol}, 2.23 \mathrm{~g})$ in absolute ethanol $(40 \mathrm{ml})$. Heat at reflux for 30 min with stirring. Cool the reaction mixture to room temperature and chill in a salted ice bath. Filter the precipitate on a Büchner and wash the precipitate with cold, absolute ethanol $(2 \times 50 \mathrm{ml})$. Crystallise the crude product from ethanol:water (1:1). Dry in vacuo. A dark red solid is obtained in a yield of $53 \%(1.78 \mathrm{~g})-\mathrm{IR}\left(\mathrm{cm}^{-1}\right.$, $\mathrm{KBr}): 3060$ (w), 2922 (m), 2853 (w), 1638 (m, alkene $\mathrm{C}=\mathrm{C}), 1610$ (s, C=O stretch), 1591 (s, C=N stretch), 1573 (s, aryl $\mathrm{C}=\mathrm{C}$ stretch), $1527(\mathrm{~m}, \mathrm{C}=\mathrm{C}$ stretch), $1475(\mathrm{~s}, \mathrm{C}=\mathrm{O}$ stretching and $\mathrm{CH}$ bending), 1430 (m), 1397 (w), 1365 (m), 1323 (w), 1230 (w), 1156 (s), 1054 (m), 947 (m), 836 (m), 757 (m), 697 (m), 604 (m) - m.p. $141^{\circ} \mathrm{C}-$ Anal. $\mathrm{C}_{99} \mathrm{H}_{101} \mathrm{~N}_{10} \mathrm{O}_{8} \mathrm{La} \quad\left(M_{\mathrm{w}}=1697.86 \mathrm{~g} \mathrm{~mol}^{-1}\right)$ : Found $\mathrm{C}$, 69.83; H, 6.09; N, 8.03\%. Calc. C, 70.04; H, 6.00; N, $8.25 \%$.

\subsection{8. (E)-N-hexadecyl-4-(2-(4-}

dimethylaminophenyl)ethenyl)pyridinium tetrakis(1,3diphenyl-1,3-propanedionato) gadolinium(III) 31

Add compound 5 ( $2 \mathrm{mmol}, 1.06 \mathrm{~g}$ ), $\mathrm{NaOH}$ ( $8 \mathrm{mmol}, 2$ $\mathrm{M}$ solution) and $\mathrm{Gd}\left(\mathrm{NO}_{3}\right)_{3} \cdot 5 \mathrm{H}_{2} \mathrm{O}(2 \mathrm{mmol}, 0.87 \mathrm{~g})$ to a solution of 1,3-diphenyl-1,3-propanedione ( $8 \mathrm{mmol}, 1.79$ $\mathrm{g})$ in absolute ethanol $(70 \mathrm{ml})$. A crystalline precipitate is formed. Heat for $30 \mathrm{~min}$ at reflux with stirring. Cool the mixture to room temperature and chill in a salted ice bath. Filter the precipitate and wash the precipitate with cold ethanol $(2 \times 50 \mathrm{ml})$. Crystallise the product from 2butanone:acetone (1:1). Dry in vacuo. Yield: $72 \%(2.20 \mathrm{~g})$ — IR ( $\left.\mathrm{cm}^{-1}, \mathrm{KBr}\right) 3057$ (w), 2928 (w), 2850 (w), 1645 (w, alkene $\mathrm{C}=\mathrm{C}$ stretch), 1592 (s, $\mathrm{C}=\mathrm{O}$ stretch), 1554 (s, aryl $\mathrm{C}=\mathrm{C}$ stretch), 1516 ( $\mathrm{s}, \mathrm{C}=\mathrm{C}$ stretch of $\beta$-diketone), 1463 (s), 1424 (s), 1367 (w), 1309 (w), 1286 (w), 1214 (w), 1165 (m), $1065(\mathrm{w}), 1022(\mathrm{w}), 955(\mathrm{w}), 720(\mathrm{~m}), 680(\mathrm{~m}), 604$ (w), 513 (w) - Anal. $\mathrm{C}_{91} \mathrm{H}_{93} \mathrm{~N}_{2} \mathrm{O}_{8} \mathrm{Gd}\left(M_{\mathrm{w}}=1499.91\right.$ $\mathrm{g} \mathrm{mol}^{-1}$ ): Found C, 72.87; H, 5.99; N, 1.73\%. Calc. C, 72.47; H, 6.25; N, $1.87 \%$.

\subsection{Determination of rare earths in the complexes}

The rare-earth content of the complexes was determined gravimetrically with 8-hydroquinoline [19]. A general procedure is: Aliquots of the complexes are weighted, so that in each batch between 15 and $20 \mathrm{mg}$ of the rare earth is expected. The weighted amount of the complex is decomposed in $20 \mathrm{ml}$ of a mixture of concentrated $\mathrm{H}_{2} \mathrm{SO}_{4}$ and concentrated $\mathrm{H}_{2} \mathrm{O}_{2}$ (in $1: 1$ ratio). Be careful! After decomposition of the complex, the solution is heated to expel the excess of $\mathrm{H}_{2} \mathrm{O}_{2}$. The solution is cooled to room temperature, $50 \mathrm{ml}$ of water is added, together with $5 \mathrm{ml}$ of a 8-hydroxyquinoline solution (3\% solution in ethanol). After addition of a slight excess of $6 \mathrm{M} \mathrm{NH}_{3}$ (faint odour of $\mathrm{NH}_{3}$ ), a green brown precipitate is formed. The solution is heated for $5 \mathrm{~min}$ at $100^{\circ} \mathrm{C}$, followed by digestion for $1 \mathrm{~h}$.
The precipitate is collected in a weighted Gooch crucible placed on a büchner funnel and the precipitate is washed thoroughly with water. The crucibles are heated in an oven at $130^{\circ} \mathrm{C}$ to constant weight. The rare-earth content in the complex is determined from the mass of the $\mathrm{Ln}\left(\mathrm{C}_{9} \mathrm{H}_{6} \mathrm{NO}\right)_{3}$ complex.

\section{Acknowledgements}

The author is Postdoctoral Fellow of the F.W.O.-Flanders (Belgium). He thanks the F.W.O. for a 'Krediet aan Navorsers', Prof. C. Görller-Walrand for laboratory facilities, and Mrs. C. Bex for helping with the preparative work. Financial support by the K.U.Leuven (GOA 98/03) and by the FWO (FWO research grant G.0243.99) is gratefully acknowledged.

\section{References}

[1] D.W. Bruce, R.G. Denning, M. Grayson, R. Le Lagadec, K.K. Lai, B.T. Pickup et al., Adv. Mater. Optics Electron. 4 (1994) 293.

[2] D. Lupo, W. Prass, U. Scheunemann, A. Laschewesky, H. Ringsdorf, I. Ledoux, J. Opt. Soc. Am. B 5 (1988) 300.

[3] U.W. Grummt, K.H. Feller, F. Lehmann, R. Colditz, R. Gadonas, A. Pugzlys, Thin Solid Films 284-285 (1996) 904.

[4] K.Z. Wang, C.H. Huang, G.X. Xu, Y. Xu, Y.Q. Liu, D.B. Zhu et al., Chem. Mater. 6 (1994) 1986.

[5] K.Z. Wang, N.Z. Wu, C.H. Huang, G.X. Xu, Y. Xu, Y.Q. Liu et al., Chem. J. Chinese Univ. 16 (1995) 1.

[6] H. Li, C.H. Huang, D. Zhou, L. Xu, T.K. Li, X.S. Zhao, X. Xie, Progr. Nat. Sci. 6 (1996) 96.

[7] L.H. Gao, K.Z. Wang, C.H. Huang, Y.F. Zhou, T.K. Li, J.M. Xu et al., Thin Solid Films 286 (1996) 237.

[8] K.Z. Wang, J. Wei, C.H. Huang, G.X. Xu, L.G. Xu, T.K. Li et al., Chem. Lett. (1994) 1761.

[9] D.J. Zhou, C.H. Huang, K.Z. Wang, G.X. Xu, X.S. Zhao, X.M. Xie et al., Langmuir 10 (1994) 1910.

[10] X.S. Zhao, X.M. Xie, X.H. Xia, H. Li, K.Z. Wang, C.H. Huang et al., Thin Solid Films 263 (1995) 13.

[11] Y.J. Xiao, X.X. Gao, C.H. Huang, K.Z. Wang, Chem. Mater. 6 (1994) 1910.

[12] K. Binnemans, C. Bex, R. Van Deun, J. Inclusion Phenom. Chem. 35 (1999) 63.

[13] K. Binnemans, C. Bex, A. Venard, H. De Leebeeck, C. GörllerWalrand, J. Mol. Liq. 83 (1999) 283

[14] D.L. Pavia, G.M. Lampman, G.S. Kriz, Introduction to Spectroscopy, A Guide for Students of Organic Chemistry, 2nd Edition, Saunders College Publishing, Orlando, 1996.

[15] B.R. Judd, Phys. Rev. 127 (1962) 750.

[16] G.S. Ofelt, J. Chem. Phys. 37 (1962) 511.

[17] C. Görller-Walrand, K. Binnemans, in: K.A. Gschneidner Jr., L. Eyring (Eds.), Handbook on the Physics and Chemistry of Rare Earths, Vol. 25, North-Holland, Amsterdam, 1998, p. 101, Chapter 167.

[18] W.T. Carnall, in: K.A. Gschneidner Jr., L. Eyring (Eds.), Handbook on the Physics and Chemistry of Rare Earths, Vol. 3, North-Holland, Amsterdam, 1979, p. 171, Chapter 24.

[19] T.I. Pirtea, Z. Anal. Chem. 107 (1936) 191. 